\title{
FINANCIAL INVESTIGATIONS TECHNIQUES AND METHODS USING IN CRIMINAL INVESTIGATIONS OF LAW-ENFORCEMENT AUTHORITIES
}

\author{
Ganna Gorbenko ${ }^{1}$ \\ ${ }^{1}$ Graduate student of Administrative Law And Administrative Procedure Department, National Academy of \\ Internal Affairs, Kyiv, Ukraine, e-mail: gorbenkogannal @gmail.com
}

\begin{abstract}
Criminal investigations became increasingly complicated by more confusing schemes used by individual criminals and criminal groups. The only way to prosecute "smart criminals" is to use financial investigation techniques. A careful financial investigation using various financial investigations tools and methods, as well as their improvement allow to conduct investigations effectively. By following the trail of the money and other assets, a financial investigation can reveal the complex structure of major criminal organization. Financial investigations reveal the proceeds of crime, as well as traces of evidence that lead investigators, detectives, analysts to the top of the hierarchy of criminal groups. Today's financial crimes are often complicated by the use of money laundering schemes. A financial investigation should be an integral part of any investigation as a whole. This requires a comprehensive approach that emphasizes financial investigations as an integral part of law enforcement efforts. Clear goals, targeted action, sufficient resources, training of investigators, detectives, analysts and the use of legally available tools are important elements of an effective financial investigation strategy in any country. The principal goal of applying financial investigative techniques is to gather information that will be admissible in court. In the study, defined financial investigation as a set of different techniques; identified problematic issues of techniques, methods and tools of financial investigations; revealed features of cooperation in financial investigations within the framework of investigation of criminal corruption offenses; offered directions of increase of their efficiency.

Keywords: financial investigation, financial investigative techniques, methods of financial investigations, types of financial investigations, evidence, intelligence, financial investigation unit, Net Worth Analysis.
\end{abstract}

JEL Classification: D30, D73, D78

Formulas: 0; fig.: 4; tabl.: 0; bibl.: 10

Introduction. The formalized processes of analyzing crime and establishing specialized units to perform these tasks are relatively new to law enforcement, stated in research «Crime Analysis: From Concept to Reality» by Steven Gottlieb and Shel Arenberg [1, P.6]. In the early 1960s, specialized criminal analysis units were responsible for detecting criminal modus operandi, investigating the nature of crimes within geographical areas, and identifying links between known criminals and crimes committed [2, p.1-8].

Criminal investigations became increasingly complicated by more confusing schemes used by individual criminals and criminal groups, so the introduction of special units in law enforcement authorities had paid off.

Steven Gottlieb and Shel Arenberg identify five processes that are inherent in the analysis of criminal offenses, such as: data collection, data verification, data analysis, data dissemination, response and evaluation [1, p.37].

Performing tasks in each of these processes requires special skills and relevant knowledge to collect, process and analyze information. Special attention is needed to be paid due to financial nature specifics of information collection and analysis. 
In Ukraine, special units in the National Police of Ukraine, the Security Service of Ukraine, the Tax Service, the Prosecutor's Office, the National Anti-Corruption Bureau of Ukraine, the State Financial Monitoring Service of Ukraine, the State Audit Office of Ukraine, the Accounting Chamber were were set up to collect, process and analyze financial information properly.

A careful financial investigation can lead from the street dealer to the kingpins. By following the trail of the money and other assets, a financial investigation can reveal the complex structure of major criminal organization [3].

The advent of criminal intelligence analysis is directly linked to the transformation of individual crime into organized or group crime. The effective use of intelligence is crucial to a law enforcement agency's ability to combat criminal groups. Through intelligence, the results will be useful in developing strategic plans to address current challenges and prepare for future expectations. Analysis of criminal intelligence allows law enforcement agencies to implement active crime response [6, p. 7].

While the use of crime analysis is appropriate to support investigations, surveillance and criminal investigations in criminal proceedings, it also provides law enforcement agencies with the ability to effectively manage resources, budgets and crime prevention functions [6, p. 7].

Why conduct financial investigations? As Willie Sutton said, "Because here is the money". Financial investigations reveal the proceeds of crime, as well as traces of evidence that lead investigators, detectives, analysts to the top of the hierarchy of criminal groups. Today's financial crimes are often complicated by the use of money laundering schemes. The only way to prosecute "smart criminals" is to use financial investigation techniques [3].

The principal goal of applying financial investigative techniques is to gather information that will be admissible in court. Most investigators will recognize that some of these techniques can be tedious and require substantial time and patience [4, p. 153].

A brief review of the basic legal principles relating to the preservation and use of evidence in white-collar criminal cases could alleviate some problems and misunderstandings in this critical area of investigation.

One problem investigators encounter is a lack of knowledge concerning the admissibility of financial documents. Too often, investigators spend countless hours gathering a vast array of documents relating to pertinent transactions necessary to prove embezzlement or financial fraud, only to find at the time of trial, or at a pretrial hearing, that he failed to obtain or to preserve the necessary evidence in admissible form [3, p. 153].

Of course, the general principles of information processing and analysis apply to the search and analysis of information used in financial investigations. Once information has been collected it must be evaluated, a stage in traditional law enforcement activity which can often be ignored. A full and proper evaluation requires the assessment of the reliability of the source and the validity of information.This stage is crucial to the intelligence process as a whole and as such 
necessitates an explanatory chapter of its own. A standardized system of evaluation has been developed using what is known as the $4 \times 4$ system, which is now widely accepted as common practice for law enforcement agencies. This system is for example used by analysts at Europol and any information received at Europol that is not evaluated will be assessed according to this system before use. Other agencies use variants of this system, but each can be easily interpreted by reference to the explanatory tables, and if necessary the information can be converted from one system to another [6, p. 25].

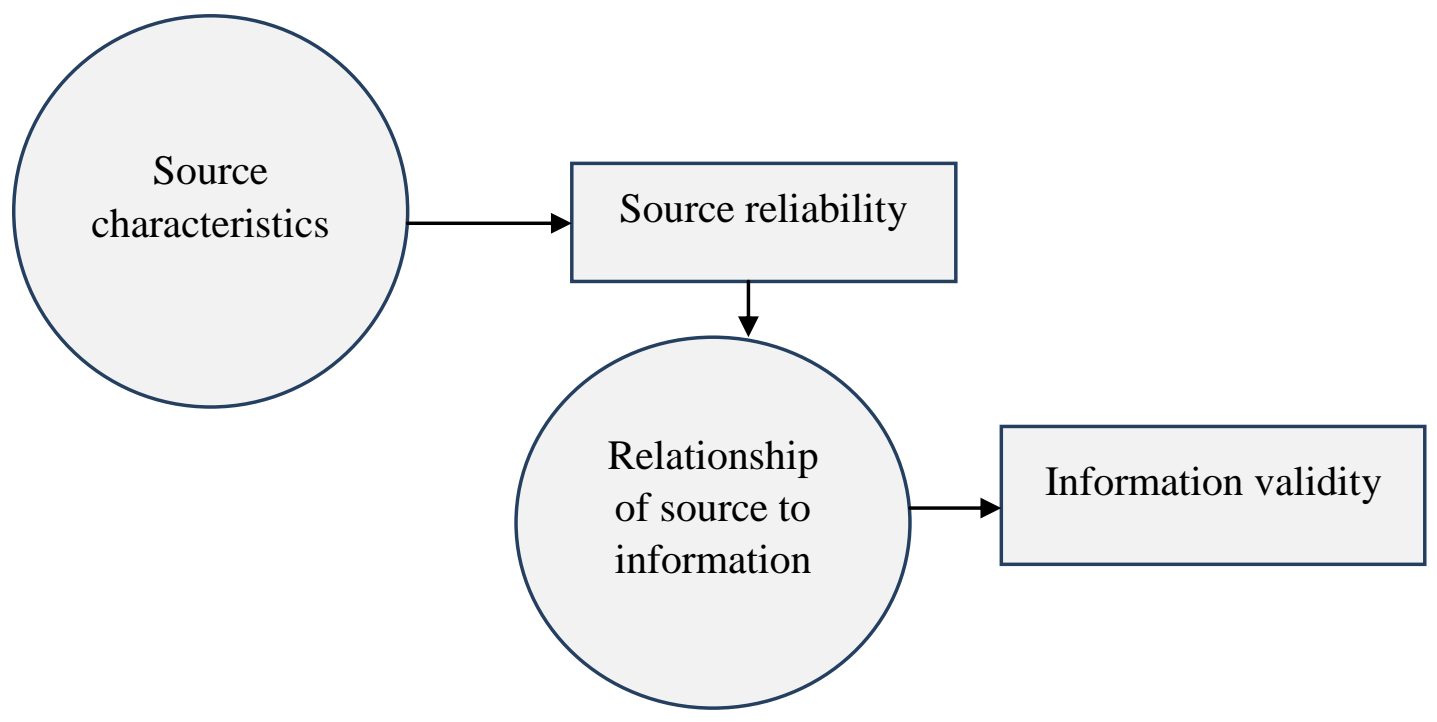

Fig.1 Information evaluation system used in financial investigations Source: [6, P.26]

Three fundamental principles apply to evaluation:

1. It must not be influenced by personal feelings but be based on professional judgement.

2. Evaluation of the source must be made separately from the information.

3. It must be carried out as close to the information source as possible. [6, P.26]

Aims are to formulate theoretical principles and categories of the financial investigations. The subject of the study is financial investigation procedure conducting by financial investigation unit and law enforcement investigators in criminal offences pre-trial investigations.

Methods. The research is based on the use of general scientific and specialscientific methods and techniques of scientific knowledge. The historical and legal method enabled to determine the preconditions for the financial investigations usage. The comparative legal method allows comparing approaches to the definition and differentiation of tasks and forms of financial investigations. The system-structural method allows determining the tasks of pre-trial investigation units in financial investigations of criminal offenses considering the functional aspect of the relevant bodies and individuals. The method of classification served as a basis to the definition of financial investigation and instruments, which allowed exploring different financial investigations instruments and methods, which allow investigating 
quickly and efficiently and collecting evidence to prove the fact of a criminal offense. In addition, this method allowed identifying different approaches to the model of financial investigations, which applied in different countries and regulated at the national and international levels, which determine the practical implementation problems and help to develop recommendations aimed at their elimination.

Results. Depending on which objects are studied (individual or legal entity), it is chosen which financial documents are collected and analyzed and, accordingly, what types of analysis are used.

The following tools are used to analyze financial information about legal entities.

Comparative Statements, also known as "horizontal analysis", are financial statements showing financial position \& profitability at different periods of time. These statements give an idea of the enterprise financial position of two or more periods. Comparison of financial statements is possible only when same accounting principles are used in preparing these statements [5]. Comparison of financial statements is possible only when the same accounting principles are used in the preparation of these reports.

For example, a comparative balance sheet can be explored by analyzing different assets and liabilities of a firm on different dates. To understand the comparative balance, it must have the data of the original balances, indicators indicating an increase or decrease in numbers, and a percentage increase or decrease.

Comparing the balance sheets of different dates, one can observe such aspects as the current financial condition and liquidity position, long-term financial position and profitability of the company.

To compare the profitability, particulars of profit \& loss are compared with the corresponding figures of previous years individually. Analyzing the profitability of the business, the changes in money value and percentage is determined.

By comparing the profits of different dates, one can observe the following aspects: the increase/decrease in gross profit, the study of operational profits, the increase or decrease in net profit, study of the overall profitability of the business [5].

Common size statements, also known as "Vertical analysis". Financial statements, when read with absolute figures, can be misleading. Therefore, a vertical analysis of financial information is done by considering the percentage form. The balance sheet items are compared: to the total assets in terms of percentage by taking the total assets as 100; to the total liabilities in terms of percentage by taking the total liabilities as 100.

Therefore the whole profit \& loss account is converted into percentage form. And such converted profit \& loss account is known as common-size profit \& loss account. As the numbers are brought to a common base, the percentage can be easily compared with the results of corresponding percentages of the previous year or of some other firms.

Trend analysis, also known as the pyramid method. Studying the operational results and financial position over a series of years is trend analysis. Calculations of ratios of different items for various periods is done \& then compared under this 
analysis. Whether the enterprise is trending upward or backward, the analysis of the ratios over a period of years is done. Adhering to this analysis, the nature of the companies is revealed [5].

Ratio analysis also known as quantitative analysis of information contained in a company's financial statements. It describes the significant relationship which exists between various items of a balance sheet and a statement of profit and loss of a company.

To assess the profitability, solvency, and efficiency of a business, investigator, detective, analyst can go through the technique of ratio analysis. It is an attempt at developing a meaningful relationship between individual items (or group of items) in the balance sheet or profit and loss account.

Cash flow analysis is used to analyze the actual cash flows within or outside a company or group of companies. The cash flow to a company is called the cash flow. Similarly, a cash outflow from a company is called a cash outflow. The difference between cash inflows and outflows is the net cash flow.

The statement of cash flows is prepared to design the method of obtaining cash and their use during the reporting year. This is an important analytical tool. Cash flow analysis explains the reason for the change in cash. This helps to assess the company's liquidity and assess the operational, investment and financial indicators needed to analyze the financial condition of the company and the nature of its activities [5].

To study the information of an individual financial statement, the main method of analysis is to compare the officially received income with the costs that individual incurs for a certain period of time. This method of calculation is also called Net Worth Analysis.

The method of Net Worth Analysis has existed for almost a century, and it is often used by investigators, detectives, analysts in criminal cases. This technique can be an effective tool in the arsenal of the investigator. However, to withstand the defense of a lawyer, the investigator and prosecutor must be attentive to the procedures and assumptions used [11].

The Net Worth Analysis method considers the difference between the value (total assets of a person less total liabilities) for any of two dates. If the gathered evidence can establish that the net worth increases more than the income received by a person in the form of money or property, less expenses, this excess will be additional illegal income for that person. The costs of living, paying taxes, etc. are also taken into account.

As the main factor is the comparison of the value of assets, official databases and open sources of information are used to collect information on such assets.

Much raw data in an investigation is collated into complex and detailed written reports. Other data pertinent to the analysis of the criminal entity or suspected criminal activity is frequently voluminous, and varied in form.

The basic problem for intelligence analysts is putting information together in an organized way so the difficult task of extracting meaning from the assembled information is made easier. 
Link analysis puts information about the relationships among entities individuals, organizations, locations, and so on - into a graphic format and context that will clarify relationships in inference development. Link analysis can be applied to relationships among those entities, which might have been identified in analysis $[6$, P.35].

To interpret the information collected by investigators, detectives, analysts, a link analysis is used, which consists of seven steps of the so-called relationship analysis:

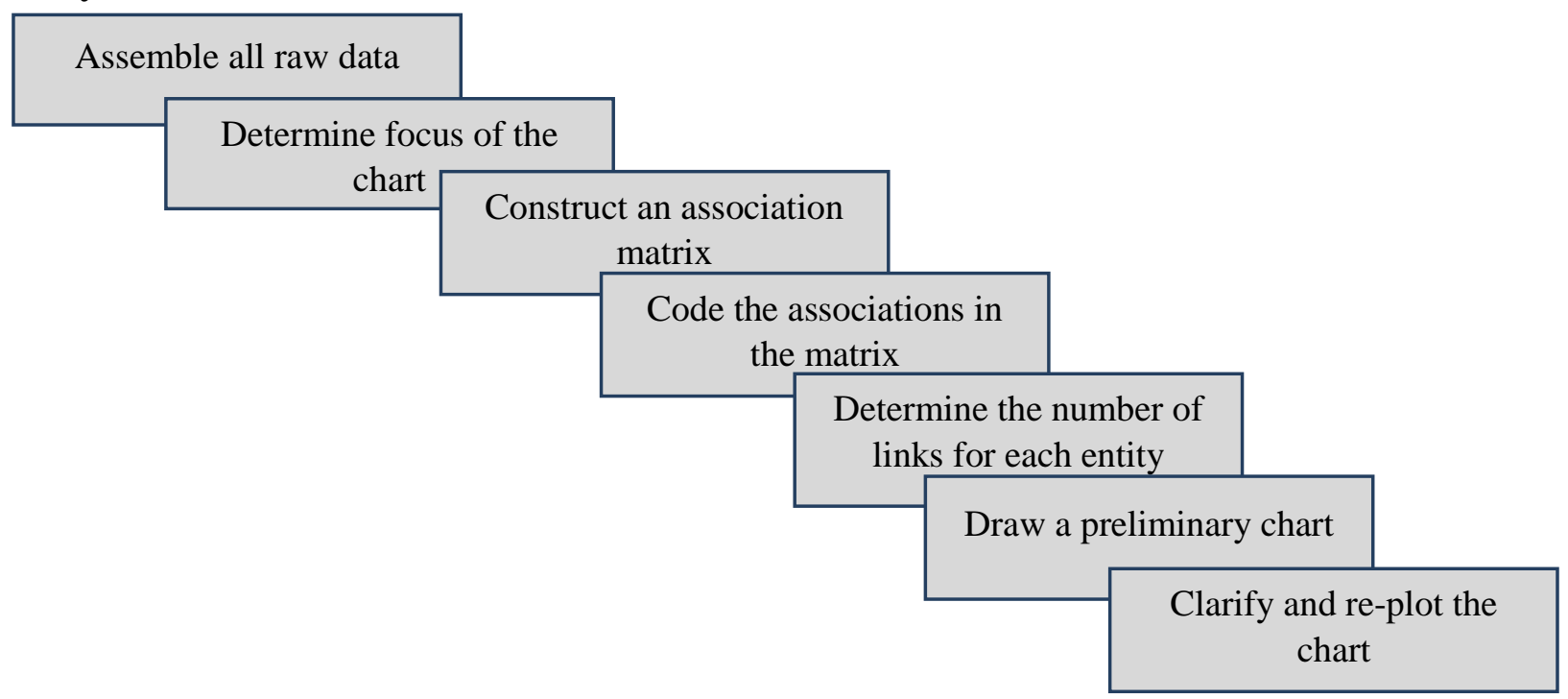

Fig. 2. Basic analysis technique: link analysis

Based on this analysis technique, you can link objects, such as individuals, legal entities, organizations, vehicles, locations, events, objects etc. The nature of the links between such objects, which can be in both directions (grant and receipt), control (criminal hierarchy), subordination and succession. Directionality relates to the flow of information, favours and authority and enables understanding of the internal mechanics of a network. Strength is a subjective judgement based on interactions included in the relationships and evaluation of the data provided. [6, P.45]

The application of a process-oriented approach to the analysis of associations, the standard seven-step process described above can be extended as follows [6, P.46].

But of course, for a clearer presentation of financial information on asset and cash flows, it will be more appropriate to use flow analysis, which can be used for different purposes. It is often used to supplement and confirm the results of the analysis of associations. The most common categories of such analysis can be: analysis of the flow of goods, analysis of activities, analysis of events. [6, P.54]

After identifying the purpose of the investigation and the qualification of the crime, the investigator, detective, analyst must obtain information and financial data and ensure the reliability and admissibility of evidence for trial. Depending on the investigation plan, the financial data may include all assets and liabilities, income and expenses of the target companies. 


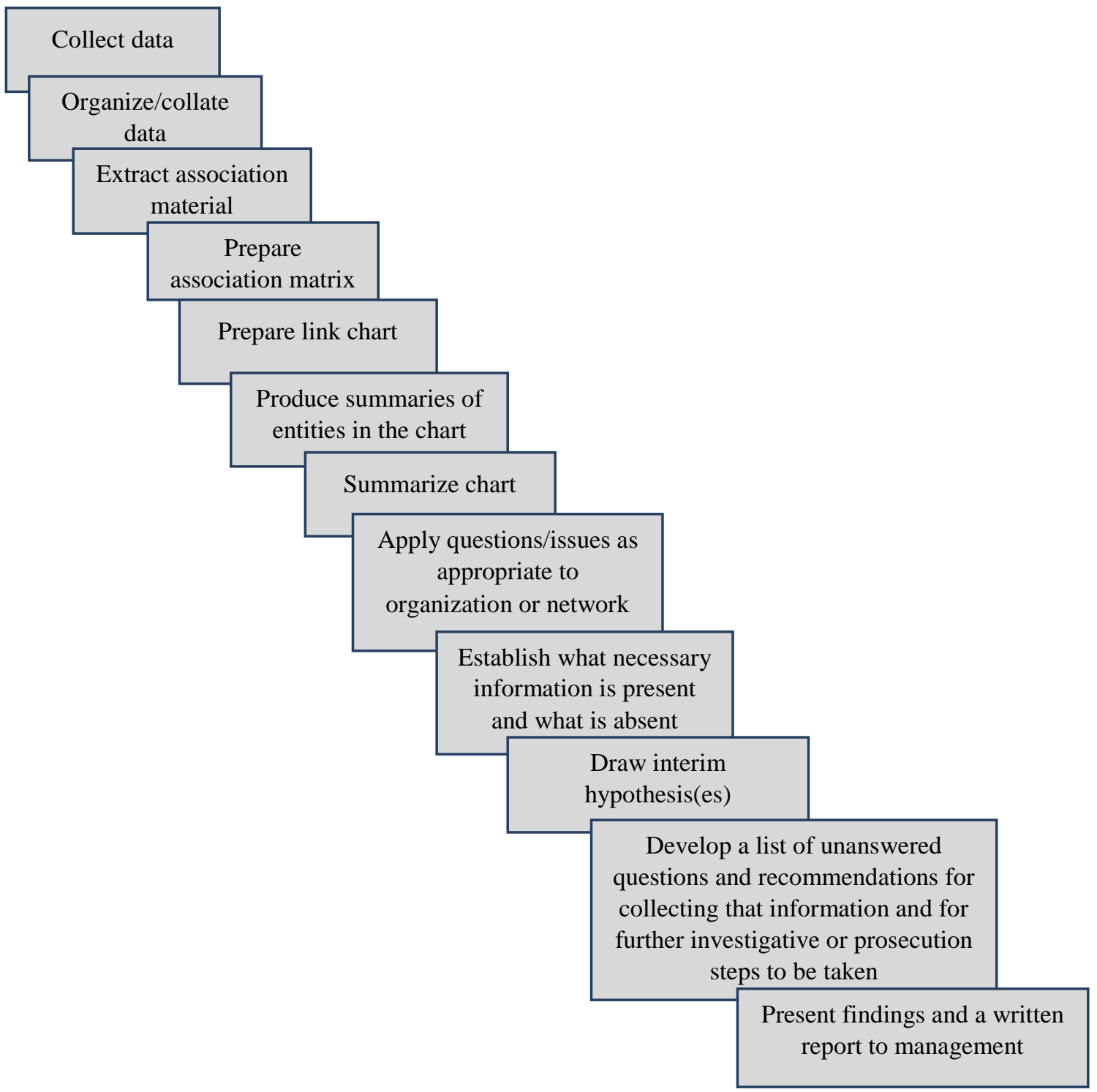

Fig.3 Advanced analysis of information based on an associative approach

Documents and other tips should be collected from a variety of sources, including the Internet and other publicly available sources; State institutions; financial institutions, including electronic banking; money service providers; law and accounting companies; service providers; real estate agents; art dealers; business competitors; travel expenses and other reward programs; information on enterprises, relatives, employees and partners of the goals and the goals themselves [7, p.7].

Investigators, detectives, and analysts typically use a variety of investigative methods that are available or permitted in all jurisdictions (depending on which methods require judicial permission or special procedures) usually for coercive measures) and which non-coercive measures, such as obtaining publicly available information and requesting information from other government agencies.

Information on assets held by target companies, their families and partners, and related businesses should be collected from official sources. Public information can be accessed on the Internet through search engines and social networks (including archival information), as well as from commercial databases, media sources and some government agencies. 
Other places to obtain financial data and other evidence: physical surveillance, fragments of discarded rubbish, cover of mail, monitoring of accounts, search and seizure warrants, permits for disclosure of information from documents or production of documents, electronic surveillance and secret transactions [7, p.7].

A financial investigation should be an integral part of any investigation as a whole. This requires a comprehensive approach that emphasizes financial investigations as an integral part of law enforcement efforts. Clear goals, targeted action, sufficient resources, training of investigators, detectives, analysts and the use of legally available tools are important elements of an effective financial investigation strategy in any country.

Creating institutional conditions that ensure close cooperation of investigators, detectives, analysts, specialized units with various competent authorities, is the basis for the success of the investigation. For example, information from tax authorities, supervisors or FIUs can help keep track of assets that may have been obtained from corruption offenses. Mechanisms that are important in promoting inter-agency cooperation include: [9]

- creation of information exchange systems, according to which all investigators, detectives, analysts would be aware of previous or current investigations conducted against the same individuals and / or legal entities in order to avoid duplication;

- introduction of policies and procedures that promote the exchange of information in the framework of interdepartmental cooperation; such policies and procedures should facilitate the strategic exchange of necessary information;

- signing written agreements, such as Memoranda of Understanding between institutions, to formalize these processes [8, p.18].

In addition, investigators, analysts, detectives can obtain the results of financial investigations conducted using various methods and techniques from specially authorized bodies (financial intelligence units). In different countries, the type of FIU, depending on the functionality may be judicial type, law enforcement type, administrative type and hybrid type, which combines elements of previous types. Depending on the type of FIU, the information they collect within financial investigations may be used as evidence in court and / or may not be used as evidence $[8$, p.20].

International cooperation is extremely important for successful investigations, in particular for financial investigations. Financial investigations often go beyond internal borders and the collection of evidence abroad is a key element in many complex criminal investigations (corruption and / or money laundering). In complex cases involving many jurisdictions, where the information held by one country is usually not sufficient to show an illegal scheme, contact with law enforcement agencies in other countries. Active exchange of information is a key factor in the investigation success.

The combination of informal cooperation between law enforcement and formal international cooperation mechanisms has led to many successful investigations of complex corruption crimes [8, p.25]. 
Conclusions. The analysis of information in the framework of financial investigations and the application of various techniques of financial information processing is clearly structured in a complex process, based on the need to verify information and separate in the general flow from information important facts $[6$, p.29].

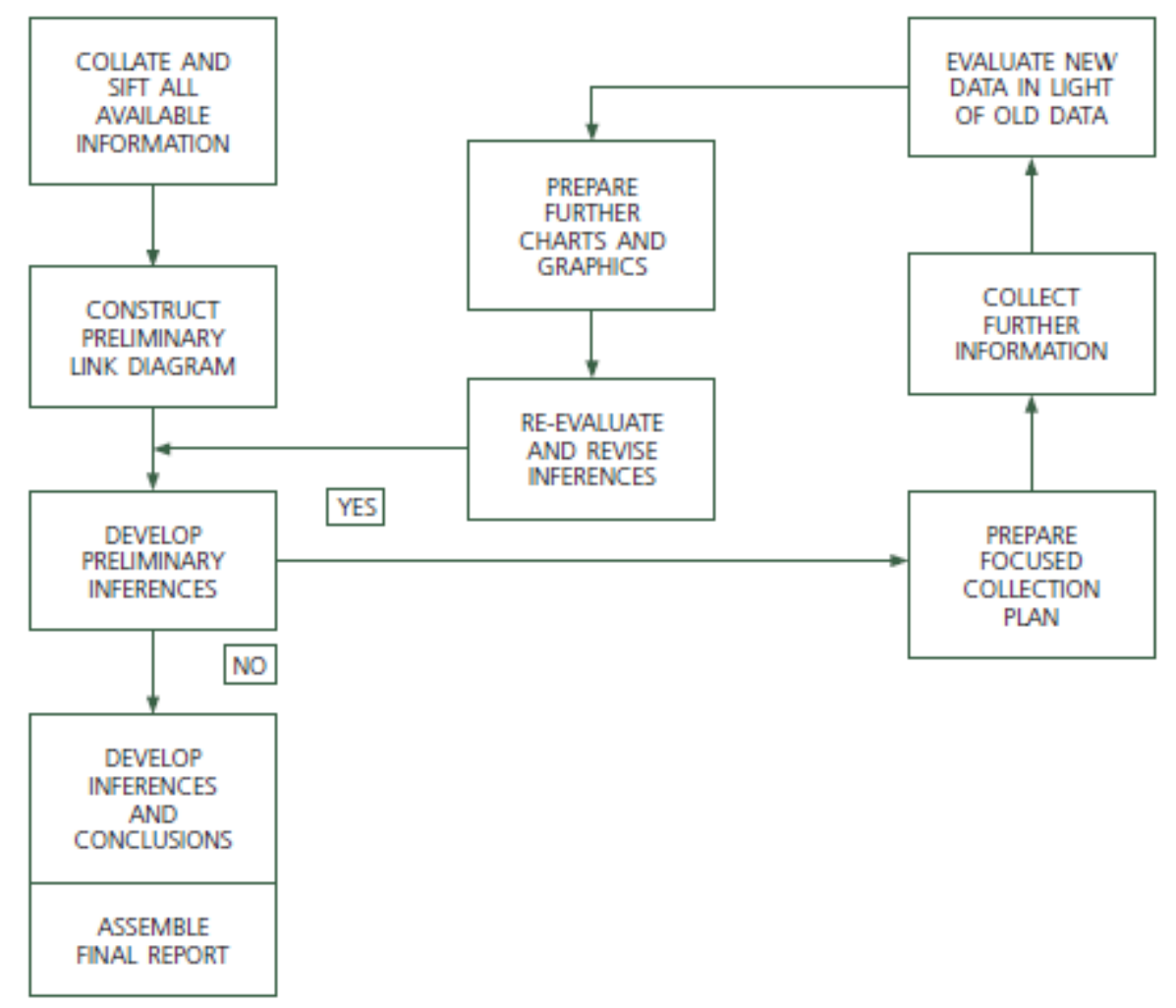

Fig. 4. The analysis of information within financial investigations

Financial investigations are becoming a key point in most criminal investigations. One of the biggest problems in complex criminal cases (such as corruption / money laundering cases) is obtaining evidence linking assets to criminal activity or proving that assets are the benefit of a crime committed by a criminal. To establish this connection (also called a "paper trail"), investigators must identify and track assets or "track money" until a connection to the offense or the location of the assets is determined. For this purpose various techniques of the analysis of financial documents are used.

The study showed that it is important to track assets using special techniques and methods of collecting, processing and analyzing information and that drawing up an investigation plan is an important first step for an effective investigation.

The urgent tasks of improving the financial investigation of complex criminal offenses are the use of new methods and means of investigation (use of special methods and techniques of analysis of financial information, its verification, procedural actions under international legal assistance, creation of joint investigation teams, etc.). It is important to implement and standardize rules and instructions for conducting financial investigations, including interagency agreements; improve national legislation in line with international law. 


\section{References:}

1. Crime Analysis: From Concept to Reality/By Steven Gottlieb and Shel Arenberg Edited By Stephen Busack, Ph.D. // Office of Criminal Justice Planning Edition. 1991.

2. Richard G. Grassie // Crime Analysis Executive Manual (U.S. Department of Justice. Law Enforcement Assistance Administration. April 1977). pp. 1-8 through 1-11.

3. United State DOJ Financial Investigation Guide// Gerald E. McDowell, Chief Asset Forfeiture and Money Laundering Section Criminal Division U.S. Department of Justice (June 1998).

4. Williams, Howard E..; Investigating White-collar Crime : Embezzlement and Financial Fraud , 2006.

5. Analysis of Financial Statements/Meaning, Significance and Objectives of Financial Analysishttps://www.toppr.com/guides/accountancy/analysis-of-financial-statements/meaning-significanceobjectives-financial-analysis.

6. Criminal Intelligence. Manual for Analysts// United Nations Office On Drugs And Crime. Vienna/New York, 2011.

7. Module 4. Planning Investigations: Investigation of Corruption and Money Laundering (adopted from the Handbook for Practitioners on Asset Recovery under StAR Initiative) Retrieved from: http://pubdocs.worldbank.org/en/ 220301427730119930/ AML-Module-4.pdf.

8. Handbook (First Part) - Best Practices in Investigating and Prosecuting Corruption Using Financial Flow Tracking Techniques and Financial Intelligence// 18th Anti-Corruption and Transparency Experts' Working Group Meeting Ningbo, China (20 February 2014).

9. FATF, Operational Issues. Financial Investigation Guidance, June 2012, p. 11; UNODC (United Nations Office on Drugs and Crime) (2004), Practical Anti-Corruption Measures for Prosecutors and Investigators, Vienna, Austria, p. 54, Retrieved from: www.unodc.org/pdf/crime/corruption/Handbook.pdf.

10. Andrew P. Ross \& Mark S. Warshavsky (2015). The Net Worth Method. Retrieved from: https://www.gettrymarcus.com/wp-content/uploads/2015/09/Insight1-The-Net-Worth-Method-revised.pdf.

Received: May 02, 2020

Approved: May 30, 2020 